\title{
ГЛОБАЛИЗАЦИЯ В МИРОВОЙ СИСТЕМЕ И ЕЕ ВЛИЯНИЕ НА КОНЦЕПЦИИ УЧЕТА И СТАТИСТИКИ *
}

\author{
(c) 2019 Петров Александр Михайлович \\ доктор экономических наук, профессор Департамента учета, анализа и аудита \\ Финансовый университет при Правительстве Российской Федерации, Россия, Москва \\ E-mail:palmi@inbox.ru
}

В данной статье будут рассмотрены факторы, способствовавшие процессу интеграции технологий глобальной экономики в процесс бухгалтерского учета. В век развития цифровых технологий все компании связаны друг с другом и быстро обмениваются информацией. Кроме того, важными являются и сами методы осуществления крупных интеграционных мероприятий, которые в дальнейшем оказывают влияние на финансовое состояние компании в целом.

Ключевые слова: глобализация, бухгалтерский учет, отчетность, концепции бухгалтерского учета, концепции статистики, транспарентность

Появление новых экономических отношений между различными странами и производителями, тенденция к снижению издержек на товары и услуги и развитие современных технологий влияет на изменения в бухгалтерском учете и статистике.

Глобализация характеризуется внедрением новых технологий общего назначения в области информации и коммуникации. Данное явление оказало влияние на все сферы экономики и социальной деятельности, например, торговлю в розничных точках, транспорт, финансовые услуги, производство, образование, здравоохранение, СМИ и так далее.

Данное явление действует также далеко за границами технологий, связанных с информацией и коммуникацией. Благодаря всемирной сети, люди получают новые возможности в создании и распространении своих идей, порождая новое содержание, новые компании и рынки.

Способов осуществления этой концепции оказалось достаточно, поскольку глубокая интеграция информационно-телекоммуникационных технологий с реальными процессами экономики той или иной страны предполагается при соблюдении общих норм, правил и стандартов.

Несомненно, возникновение информационных технологий оказало влияние и на процесс формирования отчетности коммерческих организаций. Все экономические субъекты, особенно быстро растущие и развивающиеся компании, испытывают потребность в мгновенном и бесперебойном доступе к аналитическим дан- ным, выводам и заключениям практически в каждом направлении своей деятельности - от поставок и производства до складского учета и сбыта - для того, чтобы выбирать оптимальные решения, находить скрытые возможности, предотвращать проблемы и радовать клиентов.

В ближайшем будущем значение цифровых технологий выйдет на первый план в поддержании национальных интересов страны, информационной безопасности, а также конкурентного положения Российской Федерации на мировой арене. Российская Федерация потенциально может получить шанс догнать как в цифровых технологиях, так и в других сегментах страны-лидеры.

Процесс глобализации сопровождается внедрением новых технологий, что является одним из ключевых факторов рыночной конкуренции, способствующих повышению эффективности производства и улучшению качества процессов производства продукции.

С каждым годом растут различные сферы глобальной экономики, и в настоящее время можно выделить как наиболее преобладающие следующие:

1) электронный бизнес;

2) интернет-банкинг;

3) социальную сферу;

4) образование;

5) телекоммуникации;

6) информационные системы;

7) промышленность.

Среди основных элементов глобальной эко-

* BAK 08.00.05, 08.00.14 
номики, как правило, выделяют:

- инфраструктуру, включая центры хранения, обработки и преобразования информации, центры передачи информации, программное обеспечение, средства телекоммуникаций и т.д.;

- электронные услуги органов законодательной и исполнительной государственной власти;

- бизнес-процессы хозяйствующих субъектов посредством компьютерных сетей в условиях удаленного обмена информацией между субъектами рынка;

- электронную коммерцию, которая в настоящее время является одним из наиболее перспективных направлений экономики.

Эффективное развитие рынков в глобальной экономике возможно только при наличии развитых технологий, поэтому развитие будет осуществляться в двух приоритетных направлениях. Во-первых, институты, где будут созданы возможности для развития цифровых технологий: нормативное регулирование, кадры и образование. Во-вторых, основные инфраструктурные элементы: информационная инфраструктура и информационная безопасность.

Существование глобальной мировой экономики невозможно без современных цифровых технологий.

Активно формируются программы и системы, позволяющие осуществлять централизацию предприятий, расположенных за пределами одного государства. Это позволяет эффективно и быстро достигать цели, поставленные головным подразделением компании.

Основными источниками роста в эру глобальной экономики являются:

- оптимизация производственных и логистических операций;

- повышение эффективности рынка труда;

- повышение производительности оборудования;

- повышение эффективности производства продуктов;

- снижение расходов ресурсов и производственных потерь.

В настоящее время складываются благоприятные условия для трансформации финансовой отрасли. Сегодня для традиционных игроков основные выгоды от глобальной экономики состоят в значительном ускорении вывода новых продуктов на рынок и на фоне сокращения затрат.
Совершенствование национальных систем бухгалтерского учета и статистики на основе гармонизации позволит подтянуть менее развитые в экономическом отношении страны к уровню более развитых. Информация, полученная в стандартизированных системах учета и статистики, обладающая одинаковыми качественными характеристиками, создаст объективные условия ускорения развития экономической деятельности в целом по странам.

Использование новых технологий в глобальной экономике позволит значительно увеличить прибыль малого и среднего бизнеса. Например, благодаря способности контролировать складские запасы и анализировать текущие затраты в режиме реального времени небольшой розничный магазин может избежать чрезмерного колебания запасов от дефицита до затоваривания и оптимизировать прибыльность. Особого внимания требует движение денежных средств, оптимизация которого должна обеспечиваться любой ценой. Меры, принимаемые компаниями малого и среднего предпринимательства сегодня, оказывают прямое и практически беспрепятственное влияние на их завтрашние финансовые результаты.

Имея в своем арсенале все необходимые данные, компании обретают способность действовать на опережение. Например, если компания ожидает роста стоимости материалов в течение ближайших шести месяцев, она может поэтапно повышать цены на свою продукцию, чтобы избежать значительного однократного увеличения цены.

Одним из самых многообещающих результатов растущего доступа к передовым технологиям является ускорение притока коммерческих возможностей. В частности, в сфере глобальной электронной коммерции, когда именно веб-сайт зачастую является единственным лицом компании, крайне важно, чтобы на нем отражались те же самые возможности и тот же самый потенциал, которыми располагают крупные корпорации.

Разработка программного обеспечения как услуга и облачные технологии снижают затраты компании на техническое обслуживание, поэтому инвестиции в технологии становятся все более частыми среди малого и среднего бизнеса.

В перспективе, все операции по обработке платежей, бухгалтерскому учету, маркетингу и управлению складскими запасами компании должны происходить с помощью единой систе- 
мы данных, позволяющей анализировать показатели сбыта по разным каналам. Таким образом, компания будет знать, какие услуги или товары продаются лучше всего и где, что дает компании возможность принимать нетривиальные решения, ведущие к росту объемов продаж без чрезмерного колебания запасов готовой продукции. Менеджмент компании сможет четко видеть и анализировать, что лучше всего продается через тот или иной канал сбыта и заранее планировать распределение готовой продукции.

Специалисты по финансам на всех уровнях выражают более четкое видение совместной рабочей среды, когда все более детальный финансовый анализ будет связан с быстрыми, решительными действиями в бизнесе. Такая взаимосвязь, вероятно, будет возникать даже за пределами виртуальных стен компании, затрагивая внешних партнеров в создания стоимости компании.

Финансовый аналитик в будущем будет играть еще большую роль во всех аспектах создания стоимости бизнеса. Для этого финансовые аналитики видят явную необходимость в расширении сотрудничества, большей самодостаточности в использовании технологий и более перспективном аналитическом представлении. В результате, они осознают, что они превращаются из хранителя данных в настоящих аналитиков информации.

В будущем действия финансовой функции по отношению к компании будут меньше акцентироваться на отслеживание цифр и больше на анализ того, что эти цифры означают для бизнеca.

Таким образом, можно констатировать, что в условиях глобальной мировой экономики возможности бухгалтера и аудитора расширяются, при этом и растет круг необходимых этим специалистам компетенций.

В условиях процессов цифровизации экономические субъекты должны оптимизировать использование не только находящихся в их распоряжении данных, но и той информации, которую они могут получить или выделить из обще- ния с контрагентами, из своей и экономической деятельности. Нужные данные должны быть доступны, как только в них возникает необходимость, чтобы те, кто принимает решения, могли выполнять свою работу в режиме реального времени.

Успешные программы трансформации бизнеса в условиях мировой экономики предполагают наличие амбициозных целей, достаточных ресурсов для их достижения, а также пристального внимания со стороны высшего руководства - часто в виде назначения руководителя на уровне правления, который будет нести ответственность за программу, обеспечивая контроль за ней и курируя ее наряду с другими стратегическими задачами компании.

Теперь, как никогда, специалисты по финансам признают, что все более изощренное использование аналитики станет ценным и необходимым инструментом для расширения их влияния в своих компаниях. Они также знают, что им необходимо будет использовать все имеющиеся в их распоряжении инструменты, чтобы идти в ногу с более быстро развивающейся средой принятия решений и перейти к аналитике в реальном времени. Проще говоря, им нужно улучшать использование передовых технологий для достижения целей своих компаний и их собственной карьеры.

Глобализация экономики, проявляющаяся в развитии, расширении, углублении мирового производства, глобального рынка, росте значимости информационного фактора, увеличении мобильности свободного капитала и др., обусловливает необходимость определения места национальных систем бухгалтерского учета и статистики в глобальной информационной совокупности. Соответственно, очень важно намерение стран, особенно с переходной к рынку или развивающейся экономикой, перейти на МСФО или сохранить национальные системы бухгалтерского учета и отчетности. Для успешной деятельности бизнеса необходимо предварительно оценить все плюсы и минусы перехода на новую учетную систему.

\section{Библиографический список}

1. Петров А.М. Международные стандарты финансовой отчетности: учебник. Москва. 2019.

2. Бабаев Ю.А., Петров А. М. Расчеты организации: учет, контроль и налогообложение. учебно-практическое пособие для студентов высших учебных заведений, обучающихся по специальности 080109 «Бухгалтерский учет, анализ и аудит» / Ю.А. Бабаев, А.М. Петров. Москва, 2010. Сер. Вузовский учебник 
3. Петров А.М., Мельникова Л.А. Затраты и расходы в системе бухгалтерского учета и налогообложения. Проблемы современной экономики. 2013. № 4 (48). С. 179-183.

4. Петров А.М. Организационный механизм контроля за движением дебиторской и кредиторской задолженности. Экономический анализ: теория и практика. 2006. № 18 (75). С. 54-62.

5. Бабаев Ю.А., Петров А.М. Бухгалтерский учет и контроль дебиторской и кредиторской задолженности. учеб.-практ. пособие / Ю.А. Бабаев, А.М. Петров. Москва, 2004.

6. Бабаев Ю.А. Теория бухгалтерского учета. учебник / Ю.А. Бабаев, А.М. Петров; под ред. Ю.А. Бабаева. Москва, 2011. (Изд. 5-е, перераб. и доп.)

7. Петров А.М. Контроль за движением дебиторской и кредиторской задолженности. Современный бухучет. 2004. № 9. C. 38.

8. Бабаев Ю.А., Друцикая М.В., Кеворкова Ж.А., Листопад Е.Е., Петров А. М. Бухгалтерский учет, анализ и аудит внешнеэкономической деятельности. учебник для студентов обучающихся по специальности 080109 «Бухгалтерский учет, анализ и аудит» / под редакцией Ю.А. Бабаева. Москва, 2010.

9. Мельникова Л.А., Петров А.М. Бухгалтерский учет финансовых резервов и оценочных обязательств: монография. Москва. 2015.

10. Бабаев Ю.А., Петров А.М. Бухгалтерский учет в торговле и общественном питании: учебное пособие. Москва. 2015.

11. Никифорова Е.В., Вокина Е.Б., Бердникова Л.Ф. Методические аспекты стратегического анализа в определении устойчивого развития организации // Актуальні проблеми економіки. 2015. Т. 166. № 4. С. 44-50.

12. Nikiforova E. V. Paradigm of public reporting of economic entities // World Applied Sciences Journal. 2014 . T. 29. № 5. C. 667-670.

13. Karpova T.P., Petrov A.M., Antonova O. V. Directions of Accounting Development in the Conditions of Digitalization // Jour of Adv Research in Dynamical \& Control Systems. 2018. Vol. 10, 07 -Special Issue. PP.117-125.

14. Lymar M.P., Kevorkova Z.A., Petrov A.M. The convergence of national and international accounting standards: Chinese experience // International Journal of Civil Engineering and Technology. Volume 9. Issue 13, December 2018, Pages 82-94. 